\title{
2,3-Dimethylbenzoxazolium Methosulfate
}

\author{
Atanas Kurutos ${ }^{1, *}$, Nikolai Gadjev ${ }^{1}$, Tamara Šmidlehner ${ }^{2}$, Stela Minkovska ${ }^{3}$, Ivo Piantanida ${ }^{2}$ \\ and Todor Deligeorgiev ${ }^{1}$
}

1 Department of Pharmaceutical and Applied Organic Chemistry, Faculty of Chemistry and Pharmacy, Sofia University “St. Kliment Ohridski”, 1, blv. J. Bourchier, 1164 Sofia, Bulgaria; nigadjev@abv.bg (N.G.); toddel@chem.uni-sofia.bg (T.D.)

2 Division of Organic Chemistry and Biochemistry, Ruđer Bošković Institute, Bijenička cesta 54, 10000 Zagreb, Croatia; tamara.smidlehner@gmail.com (T.Š.); Ivo.Piantanida@irb.hr (I.P.)

3 Institute of Catalysis, Bulgarian Academy of Sciences, Acad. G. Bonchev St, Bldg 11, 1113 Sofia, Bulgaria; stelamin@ic.bas.bg

* Correspondence: ohtak@chem.uni-sofia.bg; Tel.: +359-2-8161269; Fax: +359-2-9625438

Academic Editor: Norbert Haider

Received: 4 February 2016; Accepted: 1 March 2016; Published: 5 March 2016

\begin{abstract}
An economically benign solvent-free approach to synthesise 2,3-dimethylbenzoxazolium methosulfate is reported in the present work. The title compound is derived from 2-methylbenzoxazole reacting with a slight excess of dimethylsulfate, at room temperature. The reaction proceeds via an intrinsic exothermic reaction, and the benzoxazolium salt crystallized after a short time into a white crystalline form. The product was filtered off and washed with acetone and diethyl ether to provide the desired product in $89 \%$ yield. The target compound was evaluated by ESI/MS analysis.
\end{abstract}

Keywords: 2-methylbenzoxazole; dimethylsulfate; 2,3-dimethylbenzoxazolium methosulfate

\section{Introduction}

2,3-Dimethylbenzoxazolium methosulfate finds noumerous applications, including the synthesis of cyanine dyes [1-5]. The anion of the benzoxazolium salt can readily be exchanged with iodide [5], tosylate [6], perchlorate [7], or tetrafluoroborate [8]. According to literature [9], only one publication reports the synthesis of 2,3-dimethylbenzoxazolium methosulfate, in which the product is obtained by heating 2-methylbenzoxazole with dimethylsulfate for 30-40 $\mathrm{min}$ in trichloroethylene. Although the authors of this paper claim that the product of quaternization is very pure, they do not mention that methosulfate crystals are in general considered as very hygroscopic.

The stability of quaternary benzoxazolium compounds is a common issue found in both their synthesis, as well as structural studies [10]. These compounds are reported to be very sensitive to basic reagents and moisture, since the quaternary benzoxazolium compounds undergo transformation into phenols via ring opening [11-13]. This is the main reason why NMR spectra of such compounds cannot be evaluated in polar solvents including deuterated DMSO or methanol. Cationic compounds are also almost insoluble in other common NMR solvents such as deuterated chloroform of dichloromethane.

Herein we report that 2,3-dimethylbenzoxazolium methosulfate can be obtained by a solvent-free procedure, providing a very simple, economically and effective way, without heating, to obtain the desired product by a green approach. By mixing 2-methylbenzoxazole and a slight excess of dimethylsulfate, a spontaneous exothermic reaction occurred and the reaction mixture became very viscous. After $45 \mathrm{~min}$, the reaction mixture was cooled down to room temperature, it completely crystallized. Filtration, followed by washing with acetone and diethyl ether, gave white crystals in a very high yield. 


\section{Experimental Section}

\subsection{General}

Unless otherwise stated, all reagents and solvents used in the synthesis and analysis, were obtained from Sigma-Aldrich (St. Louis, MO, USA), Alfa-Aesar (Haverhill, MA, USA), as commercial products of analytical grade, and used without further purification. The ESI/MS spectra was recorded on an HPLC Agilent 1200 Series (Santa Clara, CA, USA), coupled with triple quadrupole mass spectrometer Agilent 6410. The melting point was determined on a Kofler bench and was uncorrected.

\subsection{Experimental Procedure for the Preparation of 2,3-Dimethylbenzoxazolium Methosulfate}

2-Methylbenzoxazole 1 (11.87 mL, $0.1 \mathrm{~mol}$ ) and dimethylsulfate 2 (10.42 mL, $0.11 \mathrm{~mol}$ ) (purified according to [14]) were mixed together in a $50 \mathrm{~mL}$ open flask. All operations were performed in a well-ventilated hood. After 15-20 min the reaction mixture became very viscous and self-warmed. The flask content crystallized completely after 45 minutes. The flask content was vacuum-filtered, washed with acetone and diethyl ether, and air dried yielding the product in $89 \%$, as white crystals (Scheme 1). M.p. of product $3=195-196^{\circ} \mathrm{C}$, lit. m.p. $=200^{\circ} \mathrm{C}$ [6]. The product is very hygroscopic, as it becomes semisolid if left outside a desiccator. ESI: $m / z$ : Found $\left[\mathrm{M}^{+}\right] 148.2 ; \mathrm{C}_{9} \mathrm{H}_{10} \mathrm{NO}^{+}$requires $\left[\mathrm{M}^{+}\right]$148.08; Found $\left[\mathrm{CH}_{3} \mathrm{O}_{4} \mathrm{~S}^{-}\right] 110.9$ requires $\left[\mathrm{CH}_{3} \mathrm{O}_{4} \mathrm{~S}^{-}\right] 110.98$; Copies of mass ESI/MS spectra are provided in the Supplimentary Materials.

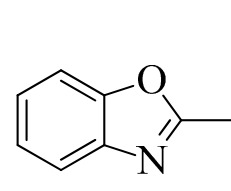

1

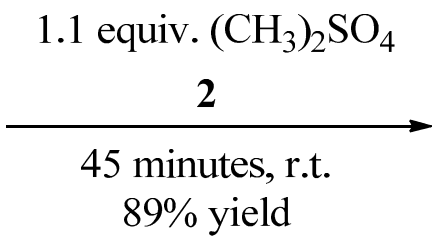

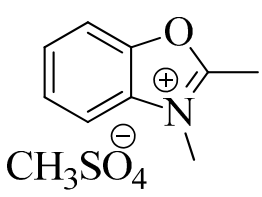

3

Scheme 1. Preparation of 2,3-dimethylbenzoxazolium methosulfate 3.

Supplementary Materials: The mass ESI/MS spectra and the molfiles are available online at http:/ / www.mdpi.com/1422-8599/2016/1/M889.

Acknowledgments: T.S. and I.P. are grateful for the financial support to "Croatian Science Foundation project 1477".

Author Contributions: The listed authors contributed to this work as following: T.D. contributed to the synthetic approach, and together with N.G. and S.M. carried out the described method. T.S. and I.P. provided the mass spectra. A.K. prepared the manuscript. All authors have read and approved the final manuscript.

Conflicts of Interest: The authors declare no conflict of interest.

\section{References}

1. Deligeorgiev, T.; Gadjev, N.; Vasilev, A.; Drexhage, K.-H.; Yarmoluk, S.M. Synthesis of novel monomeric cyanine dyes containing mercapto and thioacetyl substituents for nucleic acid detection. Dyes Pigm. 2006, 70, 185-191. [CrossRef]

2. Bethge, L.; Jarikote, D.V.; Seitz, O. New cyanine dyes as base surrogates in PNA: Forced intercalation probes (FIT-probes) for homogeneous SNP detection. Bioorg. Med. Chem. 2008, 16, 114-125. [CrossRef] [PubMed]

3. Mayerhöffer, U.; Deing, K.; Gruß, K.; Braunschweig, H.; Meerholz, K.; Würthner, F. Outstanding Short-Circuit Currents in BHJ Solar Cells Based on NIR-Absorbing Acceptor-Substituted Squaraines. Angew. Chem. Int. Ed. 2009, 48, 8776-8779. [CrossRef] [PubMed]

4. Ramos, S.S.; Santos, P.F.; Reis, L.V.; Almeida, P. Some new symmetric rigidified triheterocyclic heptamethine-cyanine dyes absorbing in the near infrared. Dyes Pigm. 2002, 53, 143-152. [CrossRef] 
5. Shi, Q.-Q.; Sun, R.; Ge, J.-F.; Xu, Q.-F.; Li, N.-J.; Lu, J.-M. A comparative study of symmetrical and unsymmetrical trimethine cyanine dyes bearing benzoxazolyl and benzothiazolyl groups. Dyes Pigm. 2012, 93, 1506-1511. [CrossRef]

6. Zanotti, K.J.; Silva, G.L.; Creeger, Y.; Robertson, K.L.; Waggoner, A.S.; Berget, P.B.; Armitage, B.A. Blue fluorescent dye-protein complexes based on fluorogenic cyanine dyes and single chain antibody fragments. Org. Biomol. Chem. 2011, 9, 1012-1020. [CrossRef] [PubMed]

7. Boev, V.I.; Moskalenko, A.I. Synthesis of full-substituted 2-methylene mercury-containing and 4-methylenemercury-containing salts of hetorocyclic cations. Zhurnal Organicheskoi Khimii 1994, 64, 1028-1031.

8. Reichardt, C.; Mormann, W. Synthesen mit substituierten Malondialdehyden, XI. $\gamma$-Formyltetramethinmerocyanin-, $\gamma$-Formyl-pentamethincyanin- und [2.2.2]Heptamethincyanin-Farbstoffe. Chem. Ber. 1972, 105, 1815-1839. [CrossRef]

9. Lochon, P. Anilinovinilbenzothiazoles et composes analogues d'autres bases hetercycliques. Bull. Soc. Chim. Fr. 1965, 2, 393-399.

10. Pardal, A.C.; Ramos, S.S.; Santos, P.F.; Reis, L.V.; Almeida, P. Synthesis and Spectroscopic Characterisation of N-Alkyl Quaternary Ammonium Salts Typical Precursors of Cyanines. Molecules 2002, 7, 320-330. [CrossRef]

11. König, W.; Meier, W. Über Thio- und Oxocyanine. J. Praktische Chem. 1925, 109, 324-344. [CrossRef]

12. Beilenson, B.; Hamer, F.M. Preparation of simple cyanines. J. Chem. Soc. 1939, 143-151. [CrossRef]

13. Hamer, F.M.; Rathbone, R.J.; Winton, B.S. Some heterocyclic methylene bases and their anilomethyl derivatives. J. Chem. Soc. 1947, 954-959. [CrossRef]

14. Armarego, W.L.F.; Chai, C.L.L. Purification of Laboratory Chemicals, 6th ed.; Butterworth-Heinemann: Oxford, UK, 2009; p. 83.

(C) 2016 by the authors; licensee MDPI, Basel, Switzerland. This article is an open access article distributed under the terms and conditions of the Creative Commons by Attribution (CC-BY) license (http:/ / creativecommons.org/licenses/by/4.0/). 